\title{
Protein TFG
}

National Cancer Institute

\section{Source}

National Cancer Institute. Protein TFG. NCI Thesaurus. Code C97836.

Protein TFG (400 aa, $43 \mathrm{kDa}$ ) is encoded by the human TFG gene. This protein is involved in the positive regulation of signal transduction. 